\title{
The Eyes: A Window into the Past
}

\author{
Nancy F. Crum-Cianflone, MD, MPH \\ Department of Internal Medicine, Division of Infectious Diseases, Naval Medical Center San \\ Diego, San Diego, CA
}

\section{Keywords}

Histoplasma capsulatum; histoplasmosis; presumed ocular histoplasmosis syndrome

\begin{abstract}
A 34-year-old woman living in southern California presents for a routine physical examination. During the eye examination, the physician notices "spots" on the retina and refers the patient to a retinal specialist.
\end{abstract}

The patient has no complaints about her vision. She has myopia ( -4.5 diopters), corrected with glasses. She has no family history of ocular disease. Her medical history is unremarkable, and she is taking no medications.

A dilated ophthalmoscopic examination of the left fundus (Figure 1) reveals atrophic, scarlike lesions that appear to be punched-out of the inner choroid (ie, "punched-out" lesions), as well as pigment deposition and peripapillary atrophy at the margin of the optic disk. Similar but fewer lesions are noted in the right eye. What is the likely diagnosis?

\section{The Most Likely Diagnosis}

The lesions raise the suspicion of histoplasmosis, but since the patient has no other evidence of histoplasmosis, the likely diagnosis is presumed ocular histoplasmosis syndrome (POHS).

Further questioning reveals that the woman grew up on a farm in the Ohio River valley, one of two areas in the United States where Histoplasma capsulatum is highly endemic. ${ }^{1}$ (The other areas is the Mississippi River valley).

As this case shows, POHS is important to consider, especially in areas where $H$ capsulatum is not endemic, to avert a lengthy workup for other causes of retinal lesions. It also shows the importance of a thorough history, including previous residences and travel. ${ }^{2}$

\section{Pathogenesis is uncertain}

In histoplasmosis, the infection is acquired by inhalation of microconidia of $H$ capsulatum, usually via disruption of the after soil (as in farming) and especially in areas where there are bird roosts. Infection is often asymptomatic, and fewer than $1 \%$ of people exposed develop a clinical illness 7-21 days after exposure. ${ }^{3}$

Correspondence: Dr. Nancy Crum-Cianflone, c/o Clinical Investigation Department (KCA), Naval Medical Center San Diego, 34800 Bob Wilson Drive, Ste. 5, San Diego, CA 92134-1005. Phone: 619/532-8134/40; FAX: 619/532-8137; nancy.crum@ med.navy.mil.

The views expressed in this article are those of the author and do not reflect the official policy or position of the Department of the Navy, Department of Defense, or the United States Government.

Conflict of interest: None. 
In disseminated histoplasmosis, eye involvement manifests as panophthalmitis or uveitis, caused by yeast implantation. The finidng of eye lesions typical of histoplasmosis but in the absence of signs of disseminated histoplasmosis - as in POHS - is much more common, seen in perhaps $1 \%$ to $5 \%$ of residents in highly endemic areas. ${ }^{4}$

The pathogenesis of POHS and its association with histoplasmosis are still unclear. ${ }^{4-7}$ Some have proposed a cellular immune response to deposited fungal antigens. Others contend that patients with specific human leukocyte antigen types (eg, B7, DR2) may be susceptible. ${ }^{4} \mathrm{H}$ capsulatum DNA has been isolated in one case of POHS, ${ }^{6}$ and the classic ocular lesions are prevalent in people who live in the Ohio River Valley ${ }^{7}$. Therefore, even though a definitive causative relationship between $H$ capsulatum exposure and POHS has not been proven, the ocular lesions are presumed to be the result of previous exposure to $H$ capsulatum, as in this case.

\section{Establishing the diagnosis of POHS}

Most cases of POHS are detected on routine eye examination. The diagnosis is confirmed by a dilated eye examination showing peripheral, punched-out, atrophic scars ("histo-spots"), which represent focal defects in the Bruch membrane, along with a history of living in an area endemic for $H$ capsulatum. Histo-spots range from 0.2 to 0.7 disk diameters and can occur as single or multiple lesions. ${ }^{8}$ Most often, both eyes are involved, albeit asymmetrically. ${ }^{9}$ Some areas may contain pigment deposits, as in this case. ${ }^{8}$ Peripapillary atrophy, a thinning of the retina immediately surrounding the head of the optic nerve, is also a characteristic of POHS. Active inflammation in the anterior chamber and vitreous are absent.

Although most patients with POHS do not have a documented diagnosis of a prior clinical Histoplasma infection, they may have a positive histoplasmin skin test, as well as lung, liver, and/or spleen calcifications. However, skin testing is not recommended as it may exacerbate $\mathrm{POHS}^{9}$, and serologic testing is usually negative. ${ }^{10}$

POHS has most commonly been diagnosed among whites ages 20-50 years (mean 35). Men and women appear to be equally affected.

\section{The potential for vision loss}

Very few patients with ophthalmoscopic evidence of POHS develop visual symptoms. ${ }^{7}$ Still, there is a risk of choroidal neovascularization at the site of the choroidal scars. These new vessels can hemorrhage, causing impaired central vision (distorted vision, blind spots).

\section{How the patient was managed}

Given that the patient had POHS with no evidence of neovascularization, she was followed with serial visual assessments using an Amsler grid. ${ }^{11}$ For POHS with choroidal neovascularization, treatment focuses on reducing the risk of vascular complications and includes oral corticosteroids, intravitreal corticosteroid injections, laser photocoagulation, and/or photodynamic therapy with verteporfin (Visudyne) ( $^{4,10,13-15}$ Antifungal treatment is not useful, as the lesions are not proven to be caused by active infection. ${ }^{10}$ Future treatments may include antiangiogenic drugs and gene therapy. ${ }^{9}$

Since her diagnosis, the patient's visual tests have been stable, with no neovascularization. 


\section{Acknowledgments}

Financial support: None.

\section{References}

1. Edwards LB, Acquaviva FA, Livesay VT, Cross FW, Palmer CE. An atlas of sensitivity to tuberculin, PPD-B, and histoplasmin in the United States. Am Rev Respir Dis. 1969; 99(Suppl):1132. [PubMed: 5767603]

2. Wheat LJ. Histoplasmosis: a review for clinicians from non-endemic areas. Mycoses. 2006; 49:27482. [PubMed: 16784440]

3. Kauffman CA. Histoplasmosis: a clinical and laboratory update. Clin Microbiol Rev. 2007; 20:11532. [PubMed: 17223625]

4. Prasad AG, Van Gelder RN. Presumed ocular histoplasmosis syndrome. Curr Opin Ophthal. 2005; 16:364-8.

5. Ongkosuwito JV, Kortbeek LM, Van der Lelij A, et al. Aetiological study of the presumed ocular histoplasmosis syndrome in the Netherlands. Br J Ophthamol. 1999; 83:535-9.

6. Spencer WH, Chan C, Shen DF, Rao NA. Detection of Histoplasma capsulatum DNA in lesions of chronic ocular histoplasmosis syndrome. Arch Ophthalmol. 2003; 121:1551-5. [PubMed: 14609910]

7. Find SL. Ocular histoplasmosis syndrome. Int Ophthalmol Clin. 1977; 17:75-87. [PubMed: 863597]

8. McMillan TA, Lashkari K. Ocular histoplasmosis. Int Ophthalmol Clinic. 1996; 36:179-86.

9. Ciulla TA, Piper HC, Xiao M, Wheat LJ. Presumed ocular histoplasmosis syndrome: update on epidemiology, pathogenesis, and photodynamic, antiangiogenic, and surgical therapies. Curr Opin Ophthalmol. 2001; 12:442-9. [PubMed: 11734684]

10. Oliver A, Ciulla TA, Comer GM. New and classic insights into presumed ocular histoplasmosis syndrome and its treatment. Curr Opin Ophthalmol. 2005; 16:160-5. [PubMed: 15870572]

11. Trevino R, Salvat R. Preventing reactivation of ocular histoplasmosis: guidance for patients at risk. Optometry. 2006; 77:10-6. [PubMed: 16458241]

12. Macular Photocoagulation Study Group. Five-year follow-up of fellow eyes of individuals with ocular histoplasmosis and unilateral extrafoveal or juxtafoveal choroidal neovascularization. Arch Ophthalmol. 1996; 114:677-88. [PubMed: 8639078]

13. Rosenfeld PJ, Saperstein DA, Bressler NM, et al. Photodynamic therapy with verteporfin in ocular histoplasmosis: uncontrolled, open-label 2-year study. Ophthalomol. 2004; 111:1725-33.

14. Shah GK, Blinder KJ, Hariprasad SM, et al. Photodynamic therapy for juxtafoveal choroidal neovascularization due to ocular histoplasmosis syndrome. Retina. 2005; 25:26-32. [PubMed: 15655437]

15. Rechtman E, Allen VD, Danis RP, et al. Intravitreal triamcinolone for choroidal neovascularization in ocular histoplasmosis syndrome. Am J Ophthalmol. 2003; 136:739-41. [PubMed: 14516819] 


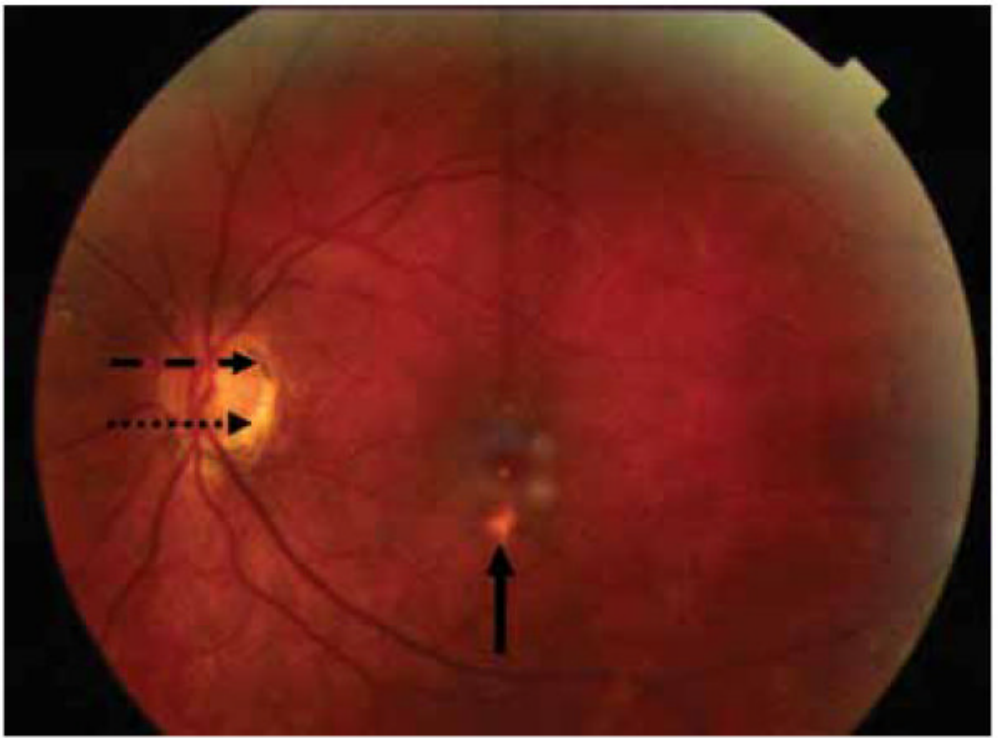

Figure 1.

The dilated eye examination shows "punched-out", atrophic scars (solid arrow), pigment deposition (dashed arrow), and peripapillary atrophy (dotted arrow). 